\title{
Effect of Scutellariae Radix Extract on Human CYP450 Mediated-Drug Metabolism
}

\author{
Hye Hyun Yoo ${ }^{\dagger}$, Sun Young Lim and Dong-Hyun Kim ${ }^{1}$ \\ College of Pharmacy, Hanyang University, Ansan, Gyeonggi-do 426-791, Korea \\ ${ }^{1}$ Department of Pharmacology, School of Medicine, Inje University, Busan 614-735, Korea \\ (Received March 24, $2011 \cdot$ Revised April 18, $2011 \cdot$ Accepted April 24, 2011)
}

\begin{abstract}
Scutellariae Radix is widely used in the traditional herbal medicine for the treatment of fever, cough, dysentery, hepatitis and hypertension in Korea, China and Japan. In this study, we investigated the effects of $70 \%$ ethanolic extract of Scutellariae Radix (SRE) on CYP450-mediated drug metabolism in the in vitro systems using human liver microsomes and hepatocytes. The microsomal incubation assay showed that SRE inhibited the drug metabolism reactions catalyzed by CYP1A2, CYP2C8 and CYP2C9 in a dose-dependent manner. In particular, SRE was shown to strongly inhibit the metabolic activity of CYP1A2 with an $\mathrm{IC}_{50}$ value of $4.6 \mu \mathrm{g} / \mathrm{mL}$. When SRE was evaluated for its effect on the induction of CYP450 enzyme activities in cryopreserved human hepatocytes, SRE did not exhibit any effect.
\end{abstract}

Key words - Scutellariae Radix, CYP450, Herb-drug interaction, Human liver microsomes, Human hepatocytes

Scutellariae Radix, dried roots of Scutellaria baicalensis Georgi, is a well-known traditional medicine used for inflammation, allergy, diarrhea, and hepatitis in Asian countries including Korea, China and Japan (Lin \& Shieh, 1996). Baicalin, baicalein, wogonin and wogonoside are known to be the major bioactive components of Scutellariae Radix (Li-Weber, 2009). Scutellariae Radix is one of the most frequently prescribed medicinal plants in traditional medicine and thus likely to be taken with other prescription drugs. Therefore, the investigation of the herb-drug interactions which could be caused by Scutellariae Radix should be required.

Cytochrome P450s (CYPs) constitute a superfamily of hemeproteins that play an important role in the metabolism of xenobiotics, including a variety of drugs (Ortiz de Montellano, 1995). Thus, if a certain substance has any effects on CYP enzyme activities, it is likely to affect the CYP-mediated drug metabolism to cause drug interactions. Several investigators have reported the effect of Scutellariae Radix on CYP enzyme activities. For example, Kim et al. (2001) reported that the water extract of Scutellariae Radix inhibited the production of aflatoxin M1 by CYP1A1/2 in rats. Several Scutellaria flavonoids such as baicalein, wogonin, and oroxylin A have been reported to inhibit CYP isozyme activities (Kim et al., 2002). Baicalin has known to modulate CYP enzymes through induction of CYP gene expression (Li et al., 2010; Fan et al., 2009). However, to our knowledge, there has been no report eval-

†Corresponding Author:

Tel : +82-31-400-5804, E-mail : yoohh@hanyang.ac.kr

DOI : $10.4333 /$ KPS.2011.41.3.143 uating collectively the possibility of herb-drug interactions by Scutellariae Radix including both CYP inhibition and induction.

In this study, we investigated the effect of $70 \%$ ethanolic extract of Scutellariae Radix (SRE) on human CYP enzyme activities to predict the likelihood of herb-drug interactions. We characterized the inhibitory effect of SRE on CYP isozymes using human liver microsomes and also inspected for its induction effect on CYP isozymes in cryopreserved human hepatocytes.

\section{Materials and Methods}

\section{Materials}

The 70\% ethanolic extract of Scutellariae Radix (SRE) was provided by Kyunghee University (Seoul, Korea). SRE was standardized to $3.78 \%$ baicalein, $19.8 \%$ baicalin, $0.62 \%$ wogonin, and $3.82 \%$ wogonoside by HPLC analysis. Human liver microsomes, cryopreserved human hepatocytes, and KHB buffer were purchased from BD Gentest corp. (Woburn, MA, USA). Glucose 6-phosphate, $\beta$-nicotinamide adenine dinucleotide phosphate $\left(\mathrm{NADP}^{+}\right)$, glucose 6-phosphate dehydrogenase phenacetine, acetaminophen, coumarine, 7-hydroxy coumarin, paclitaxel, diclofenac, 7-hydroxy diclofenac, mephenytoin, dextromethorphan, dextrophan, midazolam, 1-hydroxy midazolam, rifampicin and ascorbic acid were purchased from Sigma Chemical Co. (St. Louis, MO, USA). 4-Hydroxy mephenytoin, and 6-hydroxy paclitaxel were purchased from BD Gentest (Woburn, MA). 


\section{CYP inhibition assay}

The incubation mixtures consisted of $0.5 \mathrm{mg} / \mathrm{mL}$ human liver microsomes, various concentrations of $\operatorname{SRE}(1,5,10,50$ and $100 \mu \mathrm{g} / \mathrm{mL}$ ), a substrate mixture (Table I) and an NADPHgenerating system (NGS; $0.1 \mathrm{M}$ glucose-6-phosphate, $10 \mathrm{mg} /$ $\mathrm{mL} \beta$-NADP ${ }^{+}$and $1 \mathrm{U} / \mathrm{mL}$ glucose-6-phosphate dehydrogenase) in a total volume of $200 \mu \mathrm{L}$ potassium phosphate buffer $(0.1 \mathrm{M}, \mathrm{pH}$ 7.4). Reactions were initiated by the addition of NGS and continued for $30 \mathrm{~min}$ in a water bath at $37^{\circ} \mathrm{C}$. After the incubation, the reaction was stopped by addition of $400 \mu \mathrm{L}$ of $0.1 \%$ acetic acid and $4 \mu \mathrm{L}$ internal standard solution $(16 \mu \mathrm{M}$ terfenadine) was added. The reaction solutions were passed through activated Sep-Pak $\mathrm{C}_{18}$ cartridges (96-well type OASIS HLB extraction cartridge). Then those were washed twice with $1 \mathrm{~mL}$ distilled water and eluted with $1 \mathrm{~mL}$ methanol. The eluate was dried under nitrogen gas. The residue was resolved in $0.1 \%$ formic acid: acetonitrile $(85: 15,50 \mu \mathrm{L})$ and $5 \mu \mathrm{L}$ were injected on to the high-performance liquid chromatographic (HPLC) column for LC/MS/MS analyses.

\section{CYP induction assay}

Cryopreserved human hepatocytes were thawed at $37^{\circ} \mathrm{C}$ water bath and then centrifuged at $50 \times \mathrm{g}$ for $5 \mathrm{~min}$. The cell pellet was re-suspended in KHB buffer and diluted at $1 \times 10^{6}$ cells $/ \mathrm{mL}$. The viability of cell was tested by the trypan blue assay. Hepatocytes were seeded at density of $3 \times 10^{5} \mathrm{cell} / \mathrm{cm}^{2}$ on collagen-coated 24-well plate cultured in hepatocyte culture medium (BD Gentest, MA, USA). To investigate the effects of SRE on CYP induction, human hepatocytes were incubated with SRE $(1,10$, and $100 \mu \mathrm{g} / \mathrm{mL})$ for $72 \mathrm{~h}$. Subsequently, the media was replaced with the media containing the substrate mixture (and then further incubated for $30 \mathrm{~min}$. The incubation was stopped by adding $1 \%$ acetic acid $100 \mu \mathrm{L}$ and IS (terfenadine, $4 \mu \mathrm{L}$ of $16 \mu \mathrm{M}$ ). The reaction solutions were removed and passed through activated Sep-Pak $\mathrm{C}_{18}$ cartridges (96-well type OASIS HLB extraction cartridge). Then those were washed twice with $1 \mathrm{~mL}$ distilled water and eluted with $1 \mathrm{~mL}$ methanol. The eluate was dried under nitrogen gas. The residue was resolved in $0.1 \%$ formic acid: acetonitrile (85:15, $50 \mu \mathrm{L})$ and $10 \mu \mathrm{L}$ were injected on to the high-performance liquid chromatographic (HPLC) column for LC/MS/MS analyses. The remaining cells were scraped from wells and used for protein determination by a Bradford assay.

\section{Instruments}

The LC/MS/MS system consisted of a Nanospace SI-2 HPLC system (Shiseido, Tokyo, Japan) with an API2000 triple quadrupole mass spectrometer (Applied Biosystems-SCIEX,
Table I. CYP-specific substrates and their concentrations used in the inhibition experiments

\begin{tabular}{ccc}
\hline \hline P450 isozyme & Marker substrates & Concentration \\
\hline CYP 1A2 & Phenacetin & $40 \mu \mathrm{M}$ \\
CYP 2A6 & Coumarin & $2.5 \mu \mathrm{M}$ \\
CYP 2C8 & Paclitaxel & $10 \mu \mathrm{M}$ \\
CYP 2C9 & Diclofenac & $10 \mu \mathrm{M}$ \\
CYP 2C19 & $( \pm)$-Mephenytoin & $80 \mu \mathrm{M}$ \\
CYP 2D6 & Dextromethorphan & $5 \mu \mathrm{M}$ \\
CYP 3A4 & Midazolam & $2.5 \mu \mathrm{M}$ \\
\hline
\end{tabular}

Table II. The precursor and product ion transitions used for monitoring the metabolites generated by CYP isozymes

\begin{tabular}{ccc}
\hline \hline P450 isozyme & Metabolites & $\begin{array}{c}\text { Precursor/product ion } \\
\text { transitions }(\mathrm{m} / \mathrm{z})\end{array}$ \\
\hline CYP 1A2 & Acetaminophen & $152 / 110$ \\
CYP 2A6 & 7-OH-coumarin & $163 / 107$ \\
CYP 2C8 & 6'-OH-paclitaxel & $870 / 286$ \\
CYP 2C9 & 4'-OH-diclofenac & $312 / 230$ \\
CYP 2C19 & 4'-OH-mephenytoin & $235 / 150$ \\
CYP 2D6 & Dextrophan & $258 / 157$ \\
CYP 3A4 & 1'-OH-midazolam & $342 / 324$ \\
\hline & I.S.(terfenadine) & $472 / 436$ \\
\hline
\end{tabular}

Concord, Canada) equipped with a TurboIonSpray source. The analytical column was a CAPCELL-PAK $(2.0 \times 35 \mathrm{~mm}, 5 \mu \mathrm{m})$ and oven temperature was $50^{\circ} \mathrm{C}$. The HPLC mobile phases were as follows: $\mathrm{A}, 0.1 \%$ formic acid and $\mathrm{B}, 0.1 \%$ formic acid in acetonitrile. Separations were carried out using a gradient elution program at a flow rate of $0.2 \mathrm{~mL} / \mathrm{min}$. The initial composition was $15 \% \mathrm{~B}$, programmed linearly to increase to $90 \%$ B within $3.0 \mathrm{~min}$ and maintained at $90 \%$ B for $1.0 \mathrm{~min}$, followed by re-equilibrium to the initial condition for $2.0 \mathrm{~min}$. Total run time was $6.0 \mathrm{~min}$. The mass spectrometer Nitrogen gas was used as the nebulizing, turbo spray and curtain gas with the optimum values set at 50,50 and 20, respectively. The heated nebulizer temperature was set at $450^{\circ} \mathrm{C}$. The mass spectrometer operated with low and unit resolution for Q1 and Q3, respectively. Multiple reactions monitoring (MRM) detection was employed with dwell time of $20 \mathrm{sec}$ for each transition (Table II).

\section{Results and Discussion}

The inhibitory effects of SRB on CYP isozyme activities were evaluated in human liver microsomes. The assay system was tested with well-known CYP isozyme selective inhibitors, 
Table III. Effect of SRE on CYP isozyme activities in human liver microsomes

\begin{tabular}{ccccccccc}
\hline \hline \multirow{2}{*}{$\begin{array}{c}\mathrm{SRE} \\
(\mu \mathrm{g} / \mathrm{mL})\end{array}$} & CYP & CYP & CYP & CYP & CYP & CYP & CYP \\
& $1 \mathrm{~A} 2$ & $2 \mathrm{~A} 6$ & $2 \mathrm{C} 8$ & 2 C9 & 2C19 & 2D6 & 3A4 \\
\hline 1 & 68.1 & 62.5 & 106.1 & 78.7 & 126.9 & 120.7 & 97.3 \\
5 & 46.8 & 61.0 & 105.8 & 71.5 & 116.4 & 118.2 & 91.8 \\
10 & 33.9 & 60.4 & 98.7 & 59.3 & 107.8 & 106.9 & 84.9 \\
50 & 11.7 & 61.4 & 90.1 & 46.7 & 101.9 & 128.7 & 76.6 \\
100 & 11.2 & 57.9 & 36.2 & 36.5 & 96.4 & 110.5 & 75.5 \\
\hline
\end{tabular}

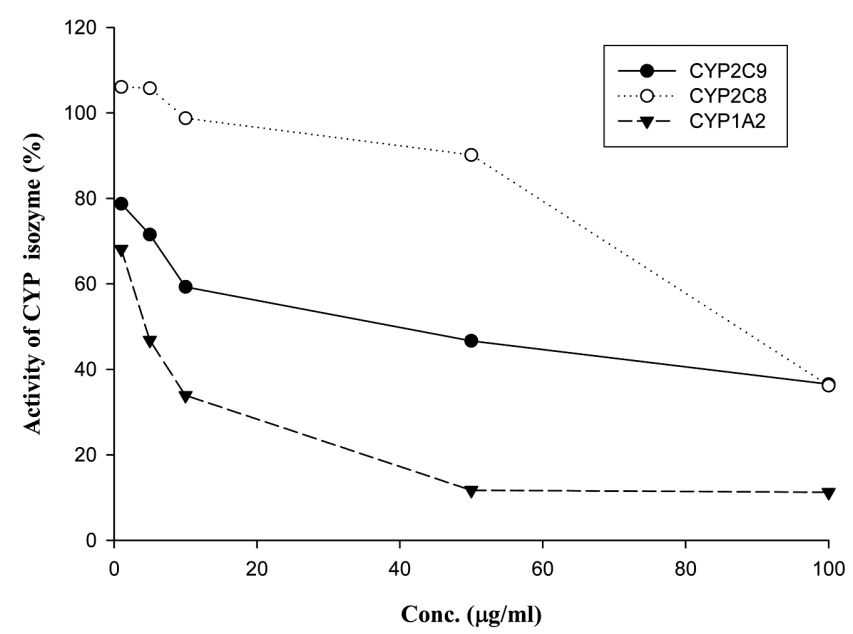

Figure 1. Inhibitory effect of SRE on the enzyme activities of CYP1A2 ( $\boldsymbol{\nabla})$, CYP2C8 (O), and CYP2C9

furafyline for CYP1A2, sulfaphenazole for CYP2C9, quinidine for CYP2D6, and ketoconazole for CYP3A4 and each inhibitor selectively inhibited the corresponding CYP marker activity (data not shown). When SRB was evaluated for its potential of CYP inhibition at concentrations of $1-100 \mu \mathrm{g} / \mathrm{mL}$, SRB showed concentration-dependent inhibitory effects on CYP1A2, CYP2C8, and CYP2C9 with the estimated $\mathrm{IC}_{50}$ values of 4.6, 89.0, and $46.3 \mu \mathrm{g} / \mathrm{mL}$, respectively (Table III and Figure 1). The effect on CYP2C8 and CYP2C9 was also not considered so significant based on their $\mathrm{IC}_{50}$ values. SRB also slightly inhibited CYP3A4 activities. However, the $\mathrm{IC}_{50}$ value was estimated to be greater than $100 \mu \mathrm{g} / \mathrm{mL}$, thus the effect on CYP3A4 could be negligible. Taken together, SRB could exert an inhibitory effect on CYP1A2-mediated drug metabolism. According to the previous report, baicalein and wogonin were reported to inhibit the CYP1A2 activities and in addition, baicalein showed the inhibitory effects on CYP2C9 and CYP3A4 activities (Kim et al., 2002). Our data is shown to be comparable to that report and baicalein and wogonin are considered to be the constituents responsible for the CYP inhibitory effects of SRE.
We also investigated the effect on the induction of CYP enzyme activities using cryopreserved human hepatocytes. First, we measured the basal activity of the hepatocytes. As a result, the enzyme activities for CYP1A2, CYP2C9 and CYP3A4 were found to be $43.2,6.8$, and $29.8 \mathrm{pmol} / \mathrm{min} / \mathrm{mg}$, respectively. Rifampicin, a well-known CYP3A4 inducer, was used as a positive control. When the cells were treated with rifampicin, the CYP3A4 activity was elevated and reached more than two times the basal activities (Table IV). Rifampicin also slightly induced the enzyme activity of CYP2C9. When SRB was tested at concentrations of 1,10 , and $100 \mu \mathrm{g} / \mathrm{mL}$, it did not show the induction effects for the CYP isozymes at any concentration tested (Table IV). Several papers raised the possibility of CYP enzyme induction by Scutellaria flavonoids such as baicalin (Li et al., 2010; Fan et al., 2009), but at least at concentrations upto $100 \mu \mathrm{g} / \mathrm{mL}$, SRE seems to have a minimal effect on CYP enzyme induction. It is notable that the CYP2C9 activity rather decreased in a dose-dependent manner by SRE. This phenomenon might be due to cytotoxicity or inhibition of CYP enzyme activities by SRE and further studies need to be done to find out the causes for this.

In conclusion, the present results showed that SRE would not induce CYP enzymes but could inhibit the CYP1A2-mediated drug metabolism. Therefore, the administration of herbal medicines including Scutellariae Radix could affect the metabolism of co-administered drugs which are metabolized by CYP1A2 to lead to herb-drug interactions.

Table IV. Effect of SRE on CYP isozyme activities in cryopreserved human hepatocytes

\begin{tabular}{lcccc}
\hline \hline Compound & Concentration & CYP1A2 & CYP2C9 & CYP3A4 \\
\hline Control & - & $100.0 \pm 4.1$ & $100.0 \pm 10.6$ & $100.0 \pm 53.7$ \\
Rifampicin & $25 \mu \mathrm{M}$ & $119.3 \pm 4.2$ & $162.3 \pm 16.8$ & $228.9 \pm 3.7$ \\
SRE & $1 \mu \mathrm{g} / \mathrm{mL}$ & $107.4 \pm 6.7$ & $99.8 \pm 14.2$ & $107.8 \pm 13.5$ \\
& $10 \mu \mathrm{g} / \mathrm{mL}$ & $95.1 \pm 2.1$ & $78.0 \pm 14.1$ & $124.7 \pm 35.9$ \\
& $100 \mu \mathrm{g} / \mathrm{mL}$ & $120.7 \pm 6.9$ & $40.6 \pm 10.8$ & $74.9 \pm 3.0$ \\
\hline
\end{tabular}




\section{References}

Fan, L., Wang, J.C., Jiang, F., Tan, Z.R., Chen, Y., Li, Q., Zhang, W., Wang, G., Lei, H.P., Hu, D.L., Wang, D., Zhou, H.H., 2009. Induction of cytochrome P450 2B6 activity by the herbal medicine baicalin as measured by bupropion hydroxylation. Eur. J. Clin. Pharmacol. 65, 403-409.

Kim, B.R., Kim, D.H., Park, R., Kwon, K.B., Ryu, D.G., Kim, Y.C., Kim, N.Y., Jeong, S., Kang, B.K., Kim, K.S., 2001. Effect of an extract of the root of Scutellaria baicalensis and its flavonoids on aflatoxin B1 oxidizing cytochrome P450 enzymes. Planta Med. 67, 396-399.

Kim, J.Y., Lee, S., Kim, D.H., Kim, B.R., Park, R., Lee, B.M., 2002. Effects of flavonoids isolated from Scutellariae radix on cytochrome P-450 activities in human liver microsomes. J.
Toxicol. Environ. Health A. 65, 373-381.

Li, Y., Wang, Q., Yao, X., Li, Y., 2010. Induction of CYP3A4 and MDR1 gene expression by baicalin, baicalein, chlorogenic acid, and ginsenoside $\mathrm{Rf}$ through constitutive androstane receptor- and pregnane $\mathrm{X}$ receptor-mediated pathways. Eur. J. Pharmacol. 640, 46-54.

Li-Weber, M., 2009. New therapeutic aspects of flavones: the anticancer properties of Scutellaria and its main active constituents wogonin, baicalein and baicalin. Cancer Treat Rev. 35, 57-68.

Lin, C.C., Shieh D.E., 1996. The anti-inflammatory activity of Scutellaria rivularis extracts and its active components, baicalin, baicalein and wogonin. Am. J. Chin. Med. 24, 31-36.

Ortiz de Montellano, P.R., 1995. Cytochrome P450: structure, mechanism, and biochemistry. Plenum Press, New York, NY, pp. 3-48. 